\title{
PARA UMA HISTÓRIA DAS CONTAS NACIONAIS NO BRASIL: ORIGENS
}

\section{TOWARDS A HISTORY OF NATIONAL ACCOUNTS IN BRAZIL: ORIGINS}

\author{
Luiz Eduardo Simões de Souza*
}

Resumo: Trata-se de uma primeira incursão em uma narrativa da implementação e desenvolvimento do Sistema de Contas Nacionais (SCN) do Brasil, criado em 1952, seguindo diretrizes da Organização das Nações Unidas. O processo de instauração, consolidação, emprego de metodologias e interpretação das diretrizes da ONU esteve, nesses quase setenta anos da adoção do sistema, longe de uma estabilidade que permitisse dados consistentes à interpretação da economia brasileira. A Fundação Getúlio Vargas e o Instituto Brasileiro de Geografia e Estatística disputaram a primazia do cálculo e a divulgação dos dados por mais de quatro décadas, além de interferências no contexto externo, que causaram divergências de entendimento e diversas revisões às séries, que são apresentadas hoje ainda como fontes capazes de fornecer coerência ao analista. Neste texto, busca-se apresentar algumas primeiras considerações para debate sobre esse tema das políticas públicas na história do Brasil republicano pós-guerra.

Palavras-chave: Sistema de Contas Nacionais; Economia Brasileira; História Econômica.

Abstract: This is an early incursion into a narrative of the implementation and development of the System of National Accounts (SNA) in

\footnotetext{
* Doutor em História Econômica, Professor Associado da Universidade Federal do Maranhão (UFMA), PPGH, PPGDSE, DECON .E-mail: luizedusouza@gmail.com
} 
Brazil, created in 1952, following the guidelines of the United Nations. The process of establishment, consolidation, use of methodologies and interpretation of UN guidelines was, in these almost seventy years since the adoption of the system, far from a stability that would allow consistent data for the interpretation of the Brazilian economy. The Getúlio Vargas Foundation (FGV) and the Brazilian Institute of Geography and Statistics (IBGE) disputed the primacy of calculation and data dissemination for more than four decades, in addition to interference in the external context, which caused divergences of understanding and several revisions to the series, which are presented today still as sources capable of providing coherence to the analyst. In this text, we seek to present some initial considerations for debate on this theme of public policies in the history of postwar republican Brazil.

Keywords: System of National Accounts; Brazilian Economy; Economic History

Resumen: Esta es una primera incursión en una narrativa de la implementación y desarrollo del Sistema de Cuentas Nacionales (SCN) de Brasil, creado en 1952, siguiendo las directrices de las Naciones Unidas. El proceso de establecimiento, consolidación, empleo de metodologías e interpretación de las directrices de la ONU estuvo, en estos casi setenta años de adopción del sistema, lejos de una estabilidad que permitiera datos consistentes para la interpretación de la economía brasileña. La Fundação Getúlio Vargas y el Instituto Brasileño de Geografia y Estadística disputaron la primacía del cálculo y la difusión de datos durante más de cuatro décadas, además de la interferencia en el contexto externo, lo que provocó divergencias de entendimiento y varias revisiones de la serie, que son presentados hoy todavía como fuentes capaces de dar coherencia al analista. En este texto, buscamos presentar algunas primeras consideraciones para el debate sobre esta cuestión de las politicas públicas en la historia del Brasil republicano de posguerra.

Palabras clave: Sistema de Cuentas Nacionales; economía brasileña; Historia Económica. 


\section{Introdução}

Ainda que se reconheçam, de maneira geral, as origens mais remotas dos sistemas de contabilidade nacional em meados do século XVII, ainda parece existir uma lacuna nessa historiografia no que diz respeito ao período entre essas origens e a criação do primeiro Sistema de Contas Nacionais pela ONU, em 1952. Isso conduz, à luz de pesquisas mais recentes, a interpretações equivocadas acerca da construção de conceitos próprios dessa área da teoria econômica que envolve a mensuração e o cálculo do produto social, ou em termos mais abrangentes, a "riqueza das nações". No caso do Brasil, quando se coloca em retrospectiva o processo de constituição das estatísticas socioeconômicas referentes ou relacionadas às contas nacionais, essa lacuna assume dimensões mais dramáticas, conduzindo a uma percepção menos ampla da Contabilidade Nacional como se essa fosse uma área que não transbordaria a teoria macroeconômica, mesmo lhe sendo basal.

Dessa forma, este texto propõe uma primeira incursão na análise do processo de implementação e desenvolvimento do Sistema de Contas Nacionais (SCN) do Brasil, criado em 1952, seguindo diretrizes da Organização das Nações Unidas. O processo de instauração, consolidação, emprego de metodologias e interpretação das diretrizes da ONU esteve, nesses quase setenta anos da adoção do sistema, longe de uma estabilidade que permitisse dados consistentes à interpretação da economia brasileira. A Fundação Getúlio Vargas e o Instituto Brasileiro de Geografia e Estatística disputaram a primazia do cálculo e a divulgação dos dados por mais de quatro décadas, além de interferências no contexto externo, que causaram divergências de entendimento e diversas revisões às séries, que são apresentadas hoje ainda como fontes capazes de fornecer coerência ao analista. Longe do que é apresentado até o momento pela historiografia, esse processo esteve longe apresentar um caráter puramente "neutro", "técnico", sem ingerências politicas que seriam, em última análise, inerentes a organizações ligadas ao Estado. Neste texto, busca-se apresentar algumas primeiras considerações para debate sobre esse tema das políticas públicas na história do Brasil republicano pós-guerra. 


\section{Antecedentes e origens do sistema de contabilidade nacional}

Conforme Studenski (1958), Vanoli (2005) e Bos (2017), a preocupação com a medida do produto social remonta às origens da Economia Política como uma ciência social moderna, ou seja, entre os séculos XVII e XIX. Além da preocupação quantitativa com os processos de produção, distribuição e circulação da riqueza pela sociedade, como bem aponta Max Weber (2012), há também uma estreita relação do desenvolvimento dessa sistemática de medida e coleta de dados com outras três frentes, a saber: (a) a Contabilidade; (b) a Estatística, em seus aspectos descritivo e inferencial, e (c) a Demografia.

Sobre essa relação tripartite, de caráter predominantemente unilateral, pode-se dizer que a contribuição dessas áreas para o estudo da renda nacional caminha quase que unicamente no subsídio dessas para a última. É possível também reconhecer três pulsos distintos das referidas áreas na construção abstrativa da renda nacional.

A Contabilidade, com seu sistema de partidas dobradas, desenvolvido ao final do século XV por Luca Pacioli, apresenta-se como a mais remota contribuição ao conceito econômico moderno de renda nacional. Sua capacidade de pronta auditoria, dada a condição de a cada débito registrado corresponder um crédito, ofereceu aos sistemas de contas nacionais, desde William Petty (circa 1693) a Robert Stone (1952), a possibilidade de analogia com a identidade entre oferta e demanda que se observa no cerne do pensamento econômico, permitindo o reconhecimento dos trânsitos de fluxos e composição de estoques de riqueza. Essa é provavelmente a pedra fundamental dos sistemas modernos de contabilidade social. Ao mesmo tempo, é possivel reconhecer um progressivo desejo de dissociação dessa herança contábil em direção a abordagens mais dinâmicas e de caráter matricial, como a de Leontief (1936). De toda forma, em sua gestação mais remota, e até sua consolidação em meados do século XX, há uma perene influência da técnica contábil de partidas dobradas na concepção da ideia de renda nacional.

A Estatística, por sua vez, observa um salto teórico-conceitual no período, tanto no aspecto descritivo, de coleta, organização, pro- 
cessamento e apresentação de dados, quanto no aspecto inferencial, de estimativa, retropolação, interpolação e previsão de informações quantitativas, a partir do desenvolvimento da teoria probabilistica e da matemática moderna, sobretudo a partir de Gauss. Distintamente da área anterior, a Estatística tem em seu desenvolvimento teórico uma recorrência intensiva na contabilidade social.

A contribuição da Demografia à contabilidade social deu-se tanto no aspecto institucional quanto no advento de técnicas censitárias. Os primeiros serviços de censo e estatística - evidentemente estatais - também recolheram a tarefa de produzir dados econômicos sobre a população. Enquanto as duas últimas apresentam um aspecto mais teórico-conceitual sobre a organização e análise dos dados, o desenvolvimento das técnicas censitárias em sua prática moldaram as características dos sistemas modernos de composição da medida das riquezas em espaços geográficos.

O século XIX, assim, observaria o desenvolvimento institucional e técnico dos serviços de censo e estatística de Estados-nações, até como forma de consolidação política dos mesmos. Nesse aspecto, as estatísticas econômicas - e as referentes à contabilidade da renda nacional - teriam centralidade na apresentação de dados seriáveis, consistentes e coesos para a análise em recorte horizontal ou transversal. Números-índices referentes à evolução dos preços, produção setorial, fluxos de comércio, contas públicas, e outros passariam a compor as sinopses estatísticas e relatórios periódicos para a análise de políticas econômicas. À burocracia dos Estados-nações seria incorporado o instrumento dos serviços de estatística, para além do caráter censitário, militar e fiscal, que os norteava até então. Entre 1790 e 1915 (BOS: 2017, p. 44), Rússia, Países Baixos, Pŕussia (depois Alemanha), Reino Unido, Estados Unidos, Itália, Aústria, Índia e Grécia apresentariam estimativas de suas rendas nacionais. A despeito da heterogeneidade da coleta, registro e apresentação dos dados (VANOLI:2005, p. 35), é notável a incorporação de dois aspectos que não deixariam de compor a pauta de preocupações desses relatórios a partir de então: uma preocupação com a diferença entre fluxos e estoques, e a noção de valor adicionado a partir de atividades produtivas. 
Sobre esse periodo, já ligado à chamada primeira fase censitária das estatísticas econômicas (SOUZA e PREVIDELLI, 2020), cabe o acréscimo da influência de dois conceitos desenvolvidos pelo pensamento econômico da época: a identidade produto-renda-dispêndio, derivada da "lei de Say" (SAY, 1803) e o conceito de equilíbrio geral de León Walras (1874), além das evidentes influências das visões sistêmicas de fluxo de renda dos Fisiocratas, ao final do século XVIII, com sua separação dos agentes por classes sociais (ou produtivas).

É necessário reconhecer que houve notório avanço, e transcendência do caráter fiscalista-militarista dos órgãos censitários no tocante ao empenho dos Estados nacionais na coleta, processamento e organização de dados econômicos, ao se observar o detalhe e a riqueza tipológica de sua execução (SOUZA e PREVIDELLI, 2020). Deve-se ressalvar a grande contribuição da Rússia, a partir de seu processo revolucionário deflagrado em 1905 e consolidado em 1917. Os serviços de estatística da Rússia bolchevique inovariam e inspirariam muitas das iniciativas do periodo posterior, com uma influência ainda hoje não suficientemente reconhecida na historiografia ocidental. A Nova Economia Politica (NEP) e os Planos Quinquenais que lhe sobrevieriam em meados da década de 1920 trariam, entre outras influências na política e planejamento econômicos, importantes adições técnicas à metodologia que a ONU adotaria na composição do primeiro Sistema de Contas Nacionais.

\section{As Nações Unidas e a padronização das estatísticas econômicas: 0 SNA-ONU 1952}

A "Era da Catástrofe" (1914 - 1945) observaria um hiato no desenvolvimento dos esforços censitários, no sentido de sua integração e padronização em nível mundial. Iniciativas de coordenação metodológica entre os serviços estatísticos nacionais, tentadas desde o final do século XIX, teriam um breve respiro nas diretrizes fundadas pela Liga das Nações em 1912, bruscamente interrompidas pela Guerra de 1914 1918, o que não impediria uma série de censos - muitos deles tardios - realizados pelo mundo durante a década de 1920. A crise de 1929 e a escalada de tensões mundiais que resultariam na Segunda Guerra Mundial (1939 - 1945) abririam outro hiato. 
Findo o conflito, a fundação da Organização das Nações Unidas (1945) representaria um novo esforço, intensificado, de retomar-se o desenvolvimento. A isso serviria o subsídio de dados consolidados em termos mundiais. Por outro lado, o arranjo geopolítico resultante à época implicava em um alinhamento bipolar que envolveria não apenas a cooperação entre países, mas também a coordenação de políticas econômicas, e mesmo a criação de blocos econômicos. Nesse contexto, um dos propósitos da ONU seria o de padronizar as estatísticas socioeconômicas de seus países-membros, permitindo, assim, a elaboração de diagnósticos e análises que possibilitassem a criação de políticas para o desenvolvimento. Para tanto, as Divisões de Estatística e População tiveram um papel de suma importância, tanto na criação e desenvolvimento de metodologias de trabalho, quanto na criação de espaços institucionais de discussão sobre temas ligados à população e desenvolvimento. Os 51 estados-membros fundadores assumiriam esse compromisso já na fundação do órgão.

A partir do relatório de uma das equipes de trabalho da ONU, Definition and measurement of the national income and related totals (1947), publicado sob a coordenação de Robert Stone, houve uma maior intensidade nos esforços junto aos países-membros para a adoção de um sistema comum de contabilidade dos dados referentes à renda nacional. Publicado em 1952, o informe A system of national accounts and supporting tables conferiria a base para o SNA-53 (System of National Accounts - 1953), considerado a pedra de toque para a elaboração de vários sistemas de contabilidade da renda nacional pelo planeta (IBGE, 2006). O Brasil, como membro-fundador da ONU, mobilizaria sua administração pública para a adoção do manual desde o início, sob forma de resolução. Os meios e trâmites dessa adoção tiveram caráter próprio e ainda hoje fornecem uma narrativa um tanto nebulosa, que já merece maior investigação.

\section{Antes da implementação do SNA-ONU no Brasil}

Situa-se na segunda metade do século XIX um interesse primário do então império brasileiro no sentido de participar de um movimento censitário dos estados nacionais no sentido de padronizar a coleta e 
processamento de dados demográficos, o qual se consubstanciaria no Censo de 1872, realizado sob as circunstâncias descritas em vasta historiografia (IBGE, 2006). As primeiras séries estatísticas que poderiam ser classificadas como estritamente econômicas foram os fluxos comerciais e financeiros captados nos portos de Salvador e Rio de Janeiro, à época do período Joanino (1808 - 1821), muito em interesse das casas comerciais interessadas em dados que permitissem às suas transações análise e planejamento. O desenvolvimento de métodos relativos à Estatística descritiva e inferencial ao longo do século XIX também foi objeto de interesse do Império, que enviou representantes aos primeiros eventos científicos internacionais organizados na Europa, com o intuito de criar pontos em comum quanto às politicas censitárias.

O desenvolvimento dos sistemas de contabilidade nacional ao longo do século XIX, por outro lado, não parece ter recebido a mesma atenção do império brasileiro, que não acompanhou as iniciativas de países como a Itália e os EUA, que tentaram construir à época modelos de cálculo do produto nacional a partir da integração do método de partidas dobradas, tomado de empréstimo à teoria contábil, com uma primeira noção de agregados econômicos, retirada em boa parte do conceito de identidade entre oferta e demanda a partir da renda, apresentado por Jean-Baptiste Say (1802), e das decorrências do conceito de equilíbrio geral desenvolvido por León Walras (1874).

A atuação do estatístico italiano Giorgio Mortara (1885 - 1967) na fundação e formação do Instituto Brasileiro de Geografia e Estatística mescla-se sobremaneira com a história da construção das estatísticas socioeconômicas no país. Entre o Censo Industrial de 1920 e o Censo Demográfico de 1940, Mortara realizou várias estimativas da atividade econômica do país, com a construção de séries históricas, das quais algumas retroagiriam ao século XIX, revisando séries originalmente apresentadas por autores como João Pandiá Calógeras (1910) e Affonso Celso Figueiredo (1902). Muitos desses dados encontram-se nos Relatórios do Banco do Brasil, publicados entre 1933 e 1966.

O caráter errático do desenvolvimento institucional do serviço público brasileiro do Segundo Império até o Estado Novo conferiria ao órgão primeiramente batizado, ainda no Império, em 1871 como Di- 
retoria Geral de Estatística ${ }^{1}$, e somente se tornaria um Instituto em 1934, uma instabilidade que tornaria os resultados apresentados sob a forma de relatórios censitários ou estatísticos como surpresas positivas, explicadas pelas iniciativas de servidores públicos ou acadêmicos tão carentes de dados, que precisariam coletá-los ou produzi-los per se. Mesmo a participação intensiva de emissários do DGE, imperial ou republicano, em todos os eventos internacionais relacionados às estatísticas demográficas ou socioeconômicas realizados entre 1870 e 1934, não seria suficiente, ao que parece, para gerar uma confiança a respeito do órgão, o que abriria espaço à iniciativa da Fundação Getúlio Vargas (FGV), no final dos anos 1940. Criada em 1944, a fundação realizava desde seu início, serviços de produção de dados socioeconômicos, apresentando na revista Conjuntura Econômica, entre outros produtos, índices de preços e produção setorial, além de estimativas de agregados econômicos baseados nos resultados dos trabalhos organizados pela ONU. Seu primeiro editor, Eugênio Gudin, viu a oportunidade de ocupar um espaço no cômputo das contas nacionais que, a seu ver, não apresentava condições de ser preenchido pelo IBGE.

\section{Algumas considerações sobre a implementação do SCN-1953: notas para uma história}

A partir desse ponto, as informações se tornam conflituosas (NUNES, 1998 e HALLAK NETO, 2014). Há versões que sustentam a plena capacidade do IBGE realizar a coleta e apresentação do relatório de Contas Nacionais, e de o Banco do Brasil fazer sua análise, sendo que a pressão de economistas ligados ao Instituto Brasileiro de Economia (IBRE), da FGV, junto ao governo, teria aberto o espaço à publicação pela revista Conjuntura Econômica, de estatísticas referentes aos agregados macroeconômicos desde 1948, e uma versão completa em 1956 (FUNDAÇÃO GETÚLIO VARGAS, 1956).

Por outro lado, há interpretações que consideram uma certa incipiência e falta de especificidade econômica da parte do IBGE, que teria criado a demanda por uma análise econômica mais apurada, que a FGV terminaria por oferecer. O fato é que, entre 1953 e 2009, a contabilidade

${ }^{1}$ Decreto, $\mathrm{n}^{\circ} 4.676$, de 14 de janeiro de 1871. 
da renda nacional do Brasil sofreu influência não apenas do próprio desenvolvimento desse ramo, mas também de uma condição institucional que levou à coexistência - nem sempre pacífica - de duas metodologias distintas.

Para além das transformações que o Sistema de Contas Nacionais sofreria, em virtude dos SNA-ONU 1963, 1972, 1986, 1993 e 2008, há uma disputa interna entre o IBGE e a FGV com mais de setenta anos de história, que envolve a disputa por espaços não apenas na discussão técnica ou teórica sobre o cálculo da riqueza nacional ou dos agregados macroeconômicos, mas também posicionamentos acerca de políticas públicas e estratégias de desenvolvimento.

O distanciamento no tempo dos agentes envolvidos com as origens da adoção do Sistema de Contabilidade Nacional da ONU no Brasil já parece permitir maior afinco e detalhe em seu exame, a fim de subsídios mais sólidos para o entendimento de seu processo de construção no entendimento da economia brasileira. Há extensa base documental nos órgãos envolvidos, e até mesmo nos que foram criados em meio a essa discussão, ao longo da segunda metade do século XX. Há não apenas relatórios, ou folhas censitárias, mas publicações paralelas a essas duas metodologias de composição de dados. Compreender seus meandros pode nos informar acerca não apenas do que economistas ou estatísticos pensaram das relações sociais produtivas no Brasil, mas também do que foi efetivamente decidido em termos de políticas públicas, por quem os consultou.

\section{Referências}

BOS, Frits. Uses of national accounts from the 17 th century till present and three suggestions for the future. EURONA - Eurostat Review on National Accounts and Macroeconomic Indicators, p. 09 - 38, 01.2017.

CALÓGERAS, João. A Politica Monetária do Brasil. Rio de Janeiro: Companhia Editora Nacional, 1960 (1910).

FIGUEREDO, Affonso Celso. A Década Republicana. Rio de Janeiro: Typ. do Brazil, 8 volumes, 1912. 
FUNDAÇÃO GETÚLIO VARGAS. Sistema de contas nacionais para o Brasil e estimativas de produto-renda e investimento. Revista de Economia Brasileira, v. 10, n. 4. Rio de Janeiro: FGV, 1956.

HALLAK NETO, João. O Sistema de Contas Nacionais - evolução, principais conceitos e sua implantação no Brasil. Rio de Janeiro: IBGE, Diretoria de Pesquisas, Coordenação de Contas Nacionais. Textos para Discussão, número 51, 2014.

IBGE. Estatísticas do século XX. Rio de Janeiro: IBGE, 2006.

KUZNETS, Simon. National income, 1929-1932. NBER Bulletin, No 49, 1934.

LEITE JÚNIOR, A. D. Renda Nacional - Teoria (tese de livre-docência). Rio de Janeiro: UFRJ, set. 1948.

LEQUILLER, F. and BLADES, D. Understanding national accounts. Paris: OECD Publishing, 2014.

LEONTIEF, Wassily. Quantitative Input and Output Relations in the Economic System of the United States, Review of Economic Statistics, Vol. 28, issue 3, pp. 105-125, 1936.

NUNES, E. P. Sistemas de contas nacionais: a gênese das contas nacionais modernas e a evolução das contas nacionais no Brasil (tese de doutorado). Campinas: Unicamp, mai. 1998.

PETTY, William. Verbum Sapienti. in Escritos Econômicos. São Paulo: Abril Cultural, 1982 (circa 1693).

QUESNAY, François. Quadro Econômico dos Fisiocratas. São Paulo: Abril Cultural, 1982 (1758).

SAY, Jean-Baptiste. Tratado de Economia Politica. São Paulo: Abril Cultural, 1982 (1802).

SHAIKH, A.; TONAK, E. Measuring the Wealth of Nations. The Political Economy of National Accounts. 
SOUZA, L. E. S. de; PREVIDELLI, M. F. S. C. Estudos Populacionais: elementos de teoria e história. Curitiba: Intersaberes, 2020.

STUDENSKI, Paul. The Income of Nations. New York: New York University Press, 1958.

VANOLI, Andre. A History of National Accounting. Amsterdam: IOS Press, 2005.

VANOLI, Andre. National Accounting at the beginning of the 21st century: Wherefrom? Whereto? EURONA - Eurostat Review on National Accounts and Macroeconomic Indicators, pp. 09 - 38, 01.2014.

WALRAS, León. Elementos de Economia Politica Pura. São Paulo: Abril Cultural, 1982 (1874).

WEBER, Max. Economia e Sociedade. Brasília: Editora da UnB, 2 volumes, 2012 (1922). 